\title{
Cuando la vocación no te permite la sana distancia
}

\author{
Lesly Marissa Nicolás Nicolás
}

\section{Resumen}

Este testimonio presenta un panorama de algunos de los retos docentes enfrentados a raíz del confinamiento por covid-19, en un Sistema de Educación de Nivel Superior. Se resalta el importante papel del docente en esta contingencia y el hecho de que no por trabajar desde casa todo es comodidad, pues la enseñanza requiere de vocación de servicio, empatía y preparación constante para la atención de necesidades no sólo académicas sino formativas en nuestros estudiantes.

Palabras clave: vocación, retos, atención, necesidades.

\section{WHEN YOUR VOCATION DOES NOT ALLOW YOU TO SOCIALLY DISTANCE}

\begin{abstract}
This experience is an overview of some of the challenges faced by teachers due to the coviD-19 sanitary contingency, in a Higher-Level Education System. We emphasize the role of the teacher in this emergency and the fact that despite working from home, this does not mean that everything is easy and comfortable, since teaching requires a vocation of service, empathy, and constant preparation for taking care of student's needs, not just in an academic context but also in formative one.
\end{abstract}

Keywords: vocation, challenges, care, needs. 


\section{Lesly Marissa Nicolás Nicolás}

LeslyM.NN@loscabos.tecnm.mx orcid.org/0000-0003-4196-1935

Profesor de Carrera de Enseñanza Superior Asociado "C" en el Tecnológico Nacional de México campus Los Cabos. Maestría en Administración por la Universidad Da Vinci y Licenciatura en Psicología por la Universidad Nacional Autónoma de México.

Cuenta con diplomados en Educación Inclusiva, Formación de Tutores del TECnM y Formación y Desarrollo de Competencias Docentes, todos por el Tecnológico Nacional de México, así como el diplomado en Formación Integral del Aprendizaje, por el Instituto Tecnológico de Estudios Superiores de Los Cabos y el de Neuropsicología Infantil, por la Universidad Autónoma de Nuevo León. Tiene las certificaciones en Tutoría en la Educación Media Superior y Superior EC0477, y de Impartición de Cursos de Formación de Capital Humano de Manera Presencial Grupal EC0217.

Docente interesada en temas de desarrollo humano, salud mental, en estrategias para fomentar la creatividad e innovación y educación integral.

Como balde de agua fría, amanecimos con la noticia de tener que entrar en confinamiento. Incredulidad, sorpresa y emociones encontradas se plasmaron ante la emergencia en nuestros estudiantes y en nosotros, los docentes. No parecía complicado enfrentar la situación, dado que, algunos huracanes de temporada nos habían obligado a trabajar bajo condiciones adversas. Sin embargo, nada ha sido parecido a lo que ya habíamos enfrentado.

Emociones negativas empezaron a fluir. El miedo a lo desconocido permeó en todos. Las noticias mostraban gradualmente un panorama mundial caótico. Muchos de nuestros estudiantes y sus familias perdieron su sustento económico. Las prioridades cambiaron: ahora no sólo se trataba de enfrentarnos a una enfermedad invisible, sino al poder resistir de la mano de una economía de emergencia. Esto fue crucial, pues nuestros estudiantes antepusieron esa supervivencia en apoyo a sus familias. Muchos dijeron adiós, otros sólo dejaron de cumplir. 
Vinieron, de manera paulatina, las secuelas del encierro, pues las semanas se convirtieron en meses. Los recursos se agotaban para muchos, y para nosotros, los recursos pedagógicos de emergencia. Comenzaron a solicitarnos mayores y mejores estrategias ante las problemáticas presentadas: deserción e implicaciones en la salud mental —que debemos atender integralmente a pesar de la distancia-, nuevos retos pedagógicos y profesionales, atención 17 horas continuas, mejora en estrategias de acercamiento empático con nuestros estudiantes; todos de la mano de un aprendizaje cada vez más exigente en tecnologías. Por ello, nuestra vida personal quedó de lado en la búsqueda por cumplir con nuestra vocación. Nuestro sentido de responsabilidad no podía permitirnos perder a ningún estudiante más.

Empezaron las pérdidas físicas de forma gradual. Esto incrementó el estrés, irritabilidad, incertidumbre y desánimo por el futuro cercano. Pensar que algún familiar o amigo podría morir aumentó las problemáticas emocionales. Así, para muchos estudiantes, iniciar un semestre no fue prioridad. Sus vidas cambiaron. Estaban vulnerables, pues, sumado a la pérdida, estaba la desolación. Tuvimos que apoyarlos. Nos dimos cuenta que lo mejor para muchos alumnos es acudir a la escuela, porque ésta se convierte en un refugio, que ahora no había presencialmente. Entonces, incluso en la virtualidad, los docentes estuvimos ahí, sin esa sana distancia que te imponen los horarios de atención, pero con el compromiso de prepararnos intensamente para atender sus necesidades.

\section{Cómo CITAR ESTE ARTículo}

* Lesly Marissa Nicolás Nicolás. (2021, enero-febrero). Cuando la vocación no te permite la sana distancia. Revista Digital Universitaria (RDU), 22(1). Dol: http://doi. org/10.22201/cuaieed.16076079e.2021.22.1.11 